\title{
Research on the Target Positioning of RMB Internationalization in the New Era
}

\author{
Dechen Ding *
}

\author{
Associate Professor \\ School of Insurance \\ Shandong University of Finance and Economics \\ Jinan 250014, China \\ Email:dechend@163.com
}

\begin{abstract}
The target orientation of RMB internationalization in the new socialist era is faced with many new situations and new characteristics. Firstly, literature on the target Orientation of RMB internationalization are reviewed, and then the environment of RMB internationalization are analysed. Eventually, through the historical comparison and logical analysis, two conclusions can be drawn as follows. First, to achieve the ultimate goal of RMB internationalization, it is necessary to reshape the international economic order. Second, the road to reshaping the new international economic order is bound to be fraught with hardships. It is bound to be accompanied by a major adjustment of the international political structure.
\end{abstract}

Keywords: New era, Internationalization of RMB, Target positioning, Systemic risk

\section{INTRODUCTION}

Socialism has entered a new era. On the one hand, China's overall national strength has reached a new level. On the other hand, new changes have taken place in the basic contradictions of socialism. The ongoing outbreak of COVID-19 has made the imbalance in world economic development even more apparent. In particular, the economic war launched by the Western countries led by the United States against China is coming with a fierce momentum, and the tide of antiglobalization is becoming more and more obvious. The internationalization of $\mathrm{RMB}$ is faced with major challenges at home and abroad, so it is vital important to carefully consider the target positioning of RMB internationalization.

\section{LITERATURE REVIEW}

\subsection{Literature review}

Wu Guanzheng (2012) argue that the goal of RMB internationalization should be positioned to speed up to become the key of the Asian regional currency, to become international currency in the fight against the dollar, the euro and the IMF's Special Drawing Rights (SDRS), the main currency basket, eventually play a key role in the international super-sovereign currency building, in order to ensure China's national interest ${ }^{[1]}$. Pan Yingli (2012) argues that the core interest of the RMB internationalization strategy lies in getting rid of the "original sin", namely, the RMB valuation of commodities and assets through international trade and international financial transactions, Chinese enterprises, financial institutions and governments involved in globalization can eliminate most of the risk of exchange rate fluctuations once and for all, and eventually to gain comprehensive international competitive advantage and initiative ${ }^{[2]}$. Ding Ningning (2015) believes that RMB internationalization is a gradual process, and its goal should not only meet China's current national capabilities, but also consider the needs of national security in the future global pattern. The goal of RMB internationalization should be to have one in three countries $^{[3]}$. Pan Yingli (2016) believes that the minimum goal of RMB internationalization should be to help China get rid of international exchange rate fluctuations and the instability of the US dollar system through the international valuation of RMB. The highest goal of RMB internationalization is to build China into a financial power and play the role of a " global bank "[4]. Liu Haohong and Li Shikai (2016) believe that RMB should be set as the strategic goal of RMB 
internationalization as six goals, including trade settlement currency, international investment currency, international reserve currency, foreign exchange transaction currency, offshore credit currency and offshore bond currency ${ }^{[5]}$. Fan Zuojun and Chang Yali (2016) set the strategic goals of RMB internationalization from the perspectives of overall and regional, near-term and long-term: the domestic goal is to expand the global space for domestic economic growth, and the international goal is to reshape the new international political and economic order ${ }^{[6]}$. Ezhihuan (2018) believed that RMB internationalization has three objectives. One is to maintain the stable status of RMB in the international monetary system. Second, accelerate the integration of China's financial market with the global financial system. Third, from the micro level, the internationalization of RMB can lock the exchange rate risk for the foreign economic and financial activities of enterprises going abroad and domestic residents, and reduce transaction costs ${ }^{[7]}$. Cheng Gui (2020) believe that The new era needs to strengthen the top-level design of RMB internationalization, define short - term, medium - term and long - term RMB internationalization goals, tasks and steps, to realize the regional expansion of RMB from "Southeast Asia and Central Asia - key countries of" One Belt and One Road "- Asia region" and the function evolution of RMB from "denomination and settlement currency - investment and financing currency - reserve currency", and continuously enhance the international influence of RMB ${ }^{[8]}$

\subsection{Literature evaluation}

In conclusion, for RMB internationalization target research mainly include two categories. Most scholars' view is that under the current international economic and financial framework, the RMB gradually get match with their own economic status of international currency status, and become the first Asian regional core currency, and then be tied with the dollar and the euro for the three major international currency. A few scholars believe that the goal of RMB internationalization is to fundamentally change the existing international economic and financial system and eventually replace THE US dollar to become the main international reserve currency ${ }^{[9]}$ (Fan Zuojun and Chang Yali, 2017).

The target positioning of RMB internationalization should be the first and most fundamental issue in the research of RMB internationalization. It is the foundation of the following researches on the path selection, risks and coping strategies, prospects and directions of RMB internationalization.

\section{ENVIRONMENTAL ANALYSIS OF RMB INTERNATIONALIZATION IN THE NEW ERA}

In recent years, many forecasters around the world believe that, in terms of the development trend of China's economy, China's total GDP will surpass that of the United States and become the largest in the world within the next five to ten years, barring an extreme event between the world and China's economy. Of course, GDP alone is not enough. China is also actively participating in improving global economic governance through various means and measures such as the Asian infrastructure investment bank, the One Belt And One Road, as well as various bilateral and multilateral free trade agreements. At the political level, in recent years, the concept of a community with a shared future for mankind has been put forward, and the concept of shared interests and win-win cooperation has been actively advocated, striving to continuously expand its influence in the global political and economic landscape. It should be said that in today's world of trade protectionism and anti-globalization, China's efforts have been echoed by many countries in the world, especially developing countries, which is favorable for promoting the process of RMB internationalization.

However, there are many unfavorable factors for the internationalization of RMB. Internally, various contradictions caused by the imbalance between economic and social development are becoming increasingly apparent, greatly restricting and hindering the healthy and benign development of China's economy and society. Sluggish capital market, increasingly severe asset bubbles, sluggish growth of real economy and worsening local government debt are undermining and hindering the ability of China's economy to develop sustainably, and the shadow of systemic financial risks is lingering. From the outside, global trade protectionism is becoming more and more fierce, and the trend of anti-globalization is more and more obvious, which makes China, a country with export-oriented economic growth mode, suffer great losses.

Therefore, in order to realize the long-term goal of RMB internationalization, two fundamental problems must be solved. First, various contradictions caused by the unbalanced economic and social development. Second, how to get rid of the negative constraints of the existing international economic and financial order. Under the leadership of the CPC Central Committee with General Secretary Xi Jinping at its core, and the Chinese people have united as one and stayed true to their original aspiration, the first problem is expected to be solved gradually through supply-side reform, expanding domestic demand and targeted poverty 
alleviation. But there is still a long way to go to solve the second problem.

\section{THE TARGET POSITIONING OF RMB INTERNATIONALIZATION}

As for the short and medium term goals and path selection of RMB internationalization, most scholars have similar opinions. That is to say, under the existing international economic and financial framework, RMB will gradually acquire the international currency status matching its own economic status and become the core currency in The Asian region. The next question is what is the long-term or ultimate goal of RMB internationalization? On this level there is a clear divide. Most scholars believe that the long-term or ultimate goal of RMB internationalization is to become one of the three major international currencies alongside US dollar and euro without breaking the existing international economic pattern. However, some scholars believe that it is necessary to reshape the international economic order and replace the US dollar as the most important international currency. Which view would be more in line with the future evolution of RMB internationalization? The determination of the ultimate goal directly determines the path choice of the subsequent RMB internationalization.

Fan Zuojun and Chang Yali (2017) ${ }^{[9]}$ believe that the high leverage of the US economy still creates great uncertainty for the world economy, and that China, which makes the biggest contribution to global economic growth, has a steady economic growth and a stable RMB is the consensus. There is some truth to these claims but they are not sufficient. In addition, it only analyzes the necessity of reforming the international economic order, but does not elaborate on the possibility and operability of the reform, which is of more important practical value for the path choice of RMB internationalization. The hegemony of the DOLLAR in the current international economic and financial order, from the economic perspective, is mainly due to the dollar's pricing power over the world's bulk commodities, such as oil, grain and various industrial raw materials ${ }^{[10]}$. Even if the ultimate goal of RMB internationalization is only to be positioned as one of the three parts of the world, the RMB is bound to have the pricing power over the world's commodities to some extent, which will inevitably erode and weaken the traditional territory of DOLLAR hegemony. And if the goal of RMB internationalization is to replace us dollar, it will fundamentally shake the hegemony economic foundation of US dollar -- the pricing power of world commodity. Another core problem is that with the deepening of RMB internationalization, the issuance and circulation of RMB must get rid of the dependence on foreign exchange reserves (mainly us dollars) and establish the RMB issuance mechanism based on China's national credit ${ }^{[10,11]}$. However, if the RMB gets rid of the credit endorsement of THE US dollar, a phenomenon similar to the decoupling of the US dollar from gold in the 1970s will inevitably occur, and a new way of credit endorsement is needed, namely the socalled "currency anchor" ${ }^{12]}$. The dollar found an alternative to oil, and its currency anchor has since been added to commodities such as grain and industrial raw materials, something China is now doing or preparing to do. It can be assumed that if the trend of global commodities denominated in renminbi starts and continues (yuan-denominated crude oil futures and iron ore futures are already listed), the US dollar will inevitably gradually lose its pricing power over oil and other commodities, and the hegemony of the US dollar will gradually weaken, and may even fundamentally collapse. In other words, with the progress of RMB internationalization, the international economic and financial order is bound to be gradually adjusted. After reaching a certain degree, qualitative changes will inevitably occur, that is, the old order will be broken and the new order will be established.

Therefore, in the short term, the internationalisation of the renminbi is temporarily not substantive threat to the monopoly of the dollar hegemony, but in the long run, the influence of the RMB and USD must be tended to decline of this long process, Unless the internationalization of the Chinese yuan stops at the tipping point of reshaping the international economic and financial order. It is conceivable that without a decisive influence on the international economic and financial order, a significant increase in the share of RMB in the international reserve currency could not be achieved at all. In particular, the current realpolitik of "America first" will not ignore the result that the gradual progress of RMB internationalization may lead to the gradual weakening of dollar hegemony.

Based on the above analysis, two conclusions can be drawn. First, to realize the ultimate goal of RMB internationalization, it is necessary to reshape the international economic order. This is the objective necessity and result with the enhancement of China's comprehensive national strength and the evolution of RMB internationalization to a certain extent. Second, reshaping the new international economic order inevitably requires a major readjustment of the international political structure, which is a long and arduous task. The internationalization of RMB will be a long and tortuous process.

As Mundell says: It is a fact of historical tradition that the strongest currency is provided by the strongest political forces. Due to the inertia of the original hegemon currency, the reconstruction of the new international economic order is bound to encounter challenges from economic, diplomatic, political and even military aspects, and the possibility of systemic financial risks, turbulence in surrounding hotspots and 
even the outbreak of color revolutions and local wars still exist. This determines that the future road of RMB internationalization will be full of hardships and frustrations. It is inevitable that there will be some stagnation and even some temporary and partial retreat. However, as the previous analysis shows, in the new era of socialism, China's comprehensive national strength is constantly improving. As long as no subversive mistakes are made, it is inevitable that China will eventually take the leading position. In this process, the adjustment of the international economic and financial order will go from quantitative to qualitative. It is predictable that the new international economic and financial order will finally be established, which conforms to the interests and well-being of most countries in the world. Therefore, the prospect of RMB internationalization process is bright. This is the objective necessity and result of the global economy with the enhancement of China's comprehensive national strength and the promotion of RMB internationalization to a certain extent.

\section{CONCLUSION}

After entering the new era of socialism, the goal orientation of RMB internationalization is faced with many new situations and new characteristics. On one hand, to realize the ultimate goal of RMB internationalization, it is necessary to reshape the international economic order. On the other hand, the road to reshape the new international economic order is bound to be fraught with hardships. It is bound to be accompanied by a major adjustment of the international political structure.

\section{ACKNOWLEDGMENTS}

I would like to show my deepest gratitude to Professor Genliang Jia, a respectable, responsible and resourceful scholar, who has provided me with valuable guidance in the writing of this thesis. I' d also like to thank all my friends and colleagues for their encouragement and support.

\section{REFERENCES}

[1] Wu Guanzheng. Analysis on the Target positioning and Path of RMB Internationalization [J]. Economist, 2012(2):83.

[2] Pan Yingli. The promotion path of RMB internationalization reflecting national core interests $[\mathrm{J}]$. International Economic Review, 2012(3):101.

[3] Ding Ningning. The Goal and Path Choice of RMB Internationalization -- The Currency Relationship Political Strategy in the Stage of Virtual Capitalism [J]. China Investment,2015(8):96.
[4] Of Pan Yingli. Correctly handle the relationship between the goal and means of RMB internationalization -- and comment on the significance of joining SDR [J]. Exploration and Contention, 2016(1):79.

[5] Liu Haohong, Li Shikai. Research on the Strategic Support System and Disequilibrium of RMB Internationalization [J]. Economist, 2016(3): 66-74.

[6] Pan Yingli. On the Strategic Objectives of RMB Internationalization $[\mathrm{J}]$. Financial Think Tank,2016(2): 20-34+135-136.

[7] Ezhihuan. Steady Development -- The New Era of China's Economy and the New Direction of RMB Internationalization [J]. Financial Review, 2018(1): 44.

[8] Cheng GUI. Research on the Advancing Path of RMB internationalization in the New Era [J]. Modern Economic Discussion, 2020(10):23-28.

[9] Fan Zuojun, Chang Yali. Consideration of RMB internationalization based on dual constraints of elements and objectives [J]. Regional Finance Research,2017(3):5-11.

[10] LAN Yonghai, Jia Linzhou, Wen Tiejun. U.S. Dollar "currency power" Strategy and China's Response [J]. World Economy and Politics,2012(3): 121-137+159-160.

[11] zhao min and gao lu. Contradiction and resolution of RMB internationalization in the context of "One Belt And One Road" -- based on criticism based on the "impossible triangle" theory $[\mathrm{J}]$. Economist, 2017(11):64-72.

[12] Yang Ronghai, Li Yabo. Analysis on the Influence of capital account opening on the status of "currency anchor" of RMB internationalization [J]. Economic Research,2017(1):134. 